\title{
FOUR-DIMENSIONAL INCOMMENSURATELY MODULATED STRUCTURE OF THULIUM POLYPHOSPHATE
}

\author{
FA-XUE Ma, DAN ZHAO *, HONG YANG, PENG-FEI CHEN, RUI-JUAN YANG, SHAN-XUAN WU \\ Department of Physics and Chemistry, Henan Polytechnic University, Jiaozuo, Henan 454000, China
}

\begin{abstract}
Single crystal of rare-earth polyphosphate $\mathrm{Tm}\left(\mathrm{PO}_{3}\right)_{3}$ has been grown under high temperature molten-salt method and structurally characterized by single crystal X-ray diffraction analysis. Using the four-dimensional superspace formalism for aperiodic structures, we performed the crystal structure refinement of $\mathrm{Tm}\left(\mathrm{PO}_{3}\right)_{3}$ as (3+1)-dimensional incommensurately modulated structure with monoclinic superspace group $C 2 / c(0,0.358,0) s 0$ and $a=14.0620(12) \AA, b=6.6612$ (6) $\AA, c=10.0191$ (9) $\AA, \beta=127.6043(9)^{\circ}, V=743.51(11) \AA^{3}, Z=4, M_{r}=405.8, D_{c}=3.626 \mathrm{~g} / \mathrm{cm}^{3}, F(000)=744, \mu_{(\mathrm{MoKa})}=12.60 \mathrm{~mm}^{-1}, R=0.048$ and $\omega R=0.050$. The structure features infinite chains of corner-sharing $\mathrm{PO}_{4}$ tetrahedra which are affected by positional modulation running along the $b$-axis. The final structure model was reasonable and did not show any unusual features.
\end{abstract}

Keywords: Crystal growth; Crystal structure; X-ray diffraction; Polyphosphate; Incommensurately modulated structure.

\section{INTRODUCTION}

In recent years, much attention has been paid to new multifunctional magnetic materials, ${ }^{[1,2]}$ phosphors, ${ }^{[3,4]}$ photocatalytic materials, ${ }^{[5]}$ and non-linear optical (NLO) materials, ${ }^{[6,7]}$ for their potential applications in several domains. It is well-known that the practical potential of a material is mostly associated with its structural characteristics, so it is meaningful to understand the detailed structure of a material for further studying its physical properties. Commonly, the crystal structure of materials can completely be characterized by three basis vectors of the translational symmetry and the coordinates of the atoms in one unit cell. However, some solids are found in recent years which give distinct $\mathrm{X}$-ray diffraction patterns but whose structures have no translational symmetry in the three-dimensional (3D) space. These so-called aperiodic crystals could be arbitrarily divided into the following three classes: modulated crystals, composite crystals and quasicrystals. Modulated and composite crystals have atomic structures that can be described as variations on periodic structures, while quasi-crystals differ from crystals with translational symmetry in a more fundamental way. All of these aperiodic crystals can be considered as periodic structures in a higher than 3D space. In the case of modulated crystals, the lacking translational periodicity in one, two, or three dimensions of the physical space can be described by one, two, or three modulation waves in different directions. To restore the periodicity, it is necessary to transform the data to ( 3 $+n) D(n=1,2$ or 3$)$ spaces. Then the symmetry of modulated crystals can be described by so-called superspace groups in which the additional periodicities are treated as a new coordinate in a higher $(3+n) D$ space. In recent years, many commensurately or incommensurately modulated compounds with intriguing structure and physical properties have been reported. ${ }^{[8-10]}$

Rare-earth phosphates with the general formula $\mathrm{Ln}\left(\mathrm{PO}_{3}\right)_{3}(\mathrm{Ln}=\mathrm{Sc}, \mathrm{Y}, \mathrm{La}-$ $\mathrm{Lu}$ ) are one of the most attractive family mainly for their optical applications. ${ }^{[11-13]}$ Their good chemical and thermal stability as well as relatively simple preparation ensure their wide application in many fields. For compound $\mathrm{Tm}\left(\mathrm{PO}_{3}\right)_{3}$, Hoppe et al. pointed out its structure is incommensurately modulated through powder X-ray diffraction analysis. ${ }^{[14]}$ However, no detailed structure was given. In this work, we prepared the single crystal of $\mathrm{Tm}\left(\mathrm{PO}_{3}\right)_{3}$, and established the detailed incommensurately modulated structure model through single-crystal X-ray diffraction method.

\section{EXPERIMENTAL}

Synthetic procedures: Raw chemicals of $\mathrm{Li}_{2} \mathrm{CO}_{3}, \mathrm{Tm}_{2} \mathrm{O}_{3}$ and $\mathrm{NH}_{4} \mathrm{H}_{2} \mathrm{PO}_{4}$ (Shanghai Reagent Factory) were analytically pure from commercial sources and used without further purification. Single crystal of $\mathrm{Tm}\left(\mathrm{PO}_{3}\right)_{3}$ was initially obtained by the high temperature molten salt reaction of $\mathrm{Li}_{2} \mathrm{CO}_{3}(0.643 \mathrm{~g}$, $8.695 \mathrm{mmol}), \mathrm{Tm}_{2} \mathrm{O}_{3}(0.0671 \mathrm{~g}, 0.1739 \mathrm{mmol})$, and $\mathrm{NH}_{4} \mathrm{H}_{2} \mathrm{PO}_{4}{ }_{4}(2.000 \mathrm{~g}, 17.39$ $\mathrm{mmol}$ ), which was thoroughly ground in an agate mortar and pressed into a pellet to ensure the best homogeneity and reactivity. The crucible was then put into an oven and heated at $1050^{\circ} \mathrm{C}$ in the air for 24 hours. In this stage, the mixture was completely melted. Afterwards, it was allowed to cool at a rate of $0.1^{\circ} \mathrm{C} / \mathrm{min}$ to $650^{\circ} \mathrm{C}$ before switching off the furnace. The flux attached to the crystal was readily dissolved in nitric acid and hot water.

Crystallography: A single crystal of $\mathrm{Tm}\left(\mathrm{PO}_{3}\right)_{3}$ with dimension of $0.20 \times$ $0.05 \times 0.05 \mathrm{~mm}$ was selected for single-crystal $\mathrm{X}$-ray diffraction determination. Data collection was performed on a Bruker APEX II CCD diffractometer with graphite-monochromated Mo-K $\alpha(\mathrm{k}=0.71073 \AA)$ radiation with an exposure time of $10 \mathrm{~s} \cdot \mathrm{deg}^{-1}$ at the temperature of $293 \mathrm{~K}$. The frames were collected at ambient temperature with a scan width of $0.5^{\circ}$ in $\omega$ and integrated with the Bruker SAINT ${ }^{[15]}$ software package using a narrow-frame integration algorithm. After that, the unit cell parameter was refined on the process of integrates using the main reflections and the second order satellite reflections. The scale module, deployed within Apex II, was used for multi-scan absorption corrections and generating *.p4p and *.hk6 files for structure solution. After that, the crystal structure of title complex was solved directly in superspace by the charge-flipping method using the Superflip program ${ }^{[16]}$ assuming kinematical diffraction intensities and subsequently refined by the JANA2006 crystallographic computing system. ${ }^{[17]}$ The details of the data collection, structure refinement, and atomic coordinates are summarized in Tab. 1. The further details of the crystal structure investigations can be obtained from the Fachinformationszentrum Karlsruhe, 76344 Eggenstein-Leopoldshafen, Germany (fax: (49)7247-808-666; e-mail: crysdata@fizkarlsruhe.de), on quoting the depository number of CSD-430665.

\section{RESULTS AND DISCUSSION}

Crystal Growth: We chose the flux method to grow crystalline $\mathrm{Tm}\left(\mathrm{PO}_{3}\right)_{3}$ used for single-crystal X-ray diffraction studies, and the $\mathrm{Li}_{2} \mathrm{O}-\mathrm{P}_{2} \mathrm{O}_{5}$ mixed salt which are easily removed by washing with water after the reaction was chosen as flux. The synthesis of $\operatorname{Tm}\left(\mathrm{PO}_{3}\right)_{3}$ in the molten salt at $1050^{\circ} \mathrm{C}$ can be expressed by the following equation:

$$
\mathrm{Tm}_{2} \mathrm{O}_{3}+6 \mathrm{NH}_{4} \mathrm{H}_{2} \mathrm{PO}_{4} \rightarrow 2 \mathrm{Tm}\left(\mathrm{PO}_{3}\right)_{3}+6 \mathrm{NH}_{3}+9 \mathrm{H}_{2} \mathrm{O}
$$

After washed in hot water, a large amount of $\mathrm{Li}_{3} \mathrm{PO}_{4}$ colorless blockshaped crystal was obtained as impurity phase. Then we have to carefully selected prism-shaped crystal of compound $\mathrm{Tm}\left(\mathrm{PO}_{3}\right)_{3}$ for single-crystal X-ray diffraction analysis.

Average structure: For incommensurately modulated structure, it is helpful to begin with the main reflections and solve the structure of the basic cell. The basic structure of $\operatorname{Tm}\left(\mathrm{PO}_{3}\right)_{3}$ features a three-dimensional (3D) framework containing $\mathrm{PO}_{4}$ tetrahedra and $\mathrm{TmO}_{6}$ octahedra (Fig. 1a). In this structure, $\mathrm{PO}_{4}$ tetrahedra are interconnected via corner-sharing $\mathrm{O}$ atoms into a 1D infinite zigzag chain running along the $c$-axis, noted as $\left(\mathrm{PO}_{3}\right)_{\infty}$ (Fig. 1b). On the other hand, each $\mathrm{Tm}$ atom is hexa-coordinated by six $\mathrm{O}$ atoms from four $\mathrm{PO}_{4}$ tetrahedra to form a distorted $\mathrm{TmO}_{6}$ octahedron. In an alternative view, $\mathrm{TmO}_{6}$ octahedra play a role to connect adjacent $\left(\mathrm{PO}_{3}\right)_{\infty}$ to from the $3 \mathrm{D}$ structure of compound $\mathrm{Tm}\left(\mathrm{PO}_{3}\right)_{3}$. It should be noted that in the refinement of average structure exceedingly large anisotropic displacement parameters (ADPs) for $\mathrm{O}$ atoms were obtained, which may be the results of strong positional modulation. 
Table 1. Experimental details for the data collection and structural refinement details of $\mathrm{Tm}\left(\mathrm{PO}_{3}\right)_{3}$.

\begin{tabular}{|c|c|}
\hline \multicolumn{2}{|l|}{ Crystal data } \\
\hline Chemical formula & $\mathrm{TmP}_{3} \mathrm{O}_{9}$ \\
\hline$M_{\mathrm{r}}$ & 405.8 \\
\hline Crystal system, space group & Monoclinic, $C 2 / c(0 \beta 0) s 0$ \\
\hline Temperature (K) & 293 \\
\hline Wave vectors & $\mathbf{q}=0.358410 \mathbf{b}^{*}$ \\
\hline$a, b, c(\AA)$ & $14.0620(12), 6.6612(6), 10.0191(9)$ \\
\hline$\beta\left({ }^{\circ}\right)$ & $127.6043(9)$ \\
\hline$V\left(\AA^{3}\right)$ & $743.51(11)$ \\
\hline$Z$ & 4 \\
\hline Radiation type & Mo $K \alpha$ \\
\hline$\mu\left(\mathrm{mm}^{-1}\right)$ & 12.60 \\
\hline Crystal size (mm) & $0.20 \times 0.05 \times 0.05$ \\
\hline \multicolumn{2}{|c|}{ Data collection } \\
\hline Diffractometer & $\begin{array}{l}\text { Bruker CCD } \\
\text { diffractometer }\end{array}$ \\
\hline Absorption correction & Multi-scan \\
\hline $\begin{array}{l}\text { No. of measured, independent and } \\
\text { observed }[I>3 \sigma(I)] \text { reflections }\end{array}$ & $10115,4512,2158$ \\
\hline$R_{\text {int }}$ & 0.068 \\
\hline$(\sin \theta / \lambda)_{\max }\left(\AA^{-1}\right)$ & 0.667 \\
\hline \multicolumn{2}{|c|}{ Refinement } \\
\hline Refinement on & $\mathrm{F}$ \\
\hline R, Rw (all reflns) & $4.78,4.12$ \\
\hline $\mathrm{R}, \mathrm{Rw}$ (main reflns) & $3.23,2.93$ \\
\hline R, Rw (first order satellites) & $5.62,5.24$ \\
\hline $\mathrm{R}, \mathrm{Rw}$ (second order satellites) & $10.84,13.26$ \\
\hline$S$ & 1.05 \\
\hline No. of reflections/parameters & $4512 / 229$ \\
\hline Weighting scheme & $w=\left[\sigma^{2}(F)+(0.01 F)^{2}\right]^{-1}$ \\
\hline No. of restraints & 1 \\
\hline$(\Delta / \mathrm{su}) \max$ & 0.0077 \\
\hline$\Delta \rho_{\max }, \Delta \rho_{\min }\left(\mathrm{e} \cdot \AA^{-3}\right)$ & $2.12,-2.34$ \\
\hline
\end{tabular}

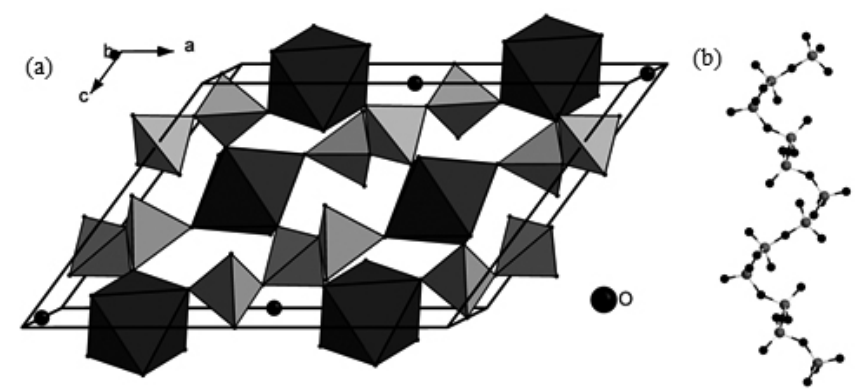

Figure 1. (a) Average structure of $\mathrm{Tm}\left(\mathrm{PO}_{3}\right)_{3}$ to show the connection of $\mathrm{TmO}_{6}$ octahedra and $\mathrm{PO}_{4}$ tetrahedra; (b) $1 \mathrm{D}$ infinite $\left(\mathrm{PO}_{3}\right)_{\infty}$ chain running along the $c$-axis.
Incommensurately modulated structure: The standard method for handling incommensurately modulated structures is to use the superspace approach. After careful examination of the reciprocal lattice constructed from experimental CCD images (Fig. 2), it is obviously shown that in addition to the main reflections located on points of reciprocal lattice, the diffraction pattern also contained strong satellite reflections that could be indexed with four integers as $\mathbf{H}=h \mathbf{a}^{*}+k \mathbf{b}^{*}+l \mathbf{c}^{*}+m \mathbf{q}\left(\mathbf{a}^{*}, \mathbf{b}^{*}\right.$, and $\mathbf{c}^{*}$ are the basis vectors of the 3 -D reciprocal lattice). The modulation vector $\mathbf{q}$ can be expressed as $\mathbf{q}=\alpha \mathbf{a}^{*}$ $+\beta \mathbf{b}^{*}+\gamma \mathbf{c}^{*}$, where $\alpha, \beta$, and $\gamma$ are numbers which are rational for commensurate cases and irrational for incommensurate cases. The final $\mathbf{q}$ vector was refined to be 0.358 , which is significantly different from any simple commensurate value. Thus the structure of compound $\mathrm{Tm}\left(\mathrm{PO}_{3}\right)_{3}$ can be considered to be incommensurate modulation.

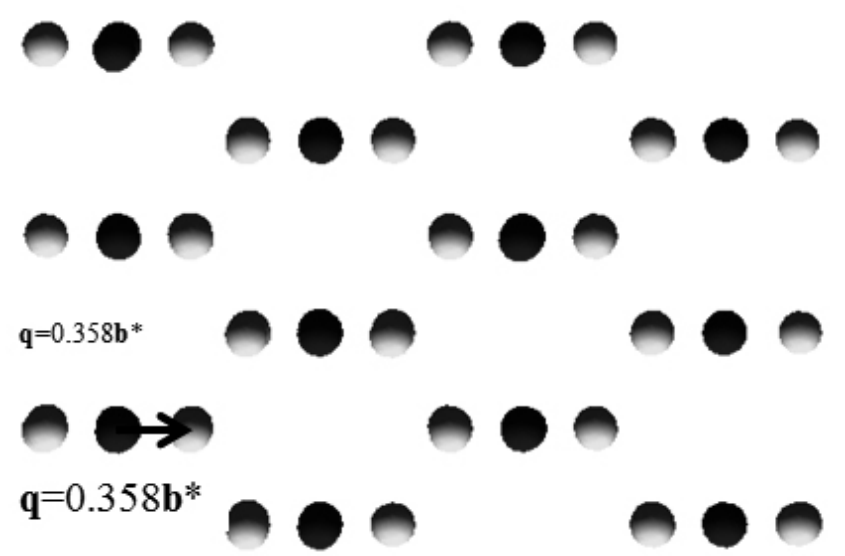

Figure 2. Reciprocal lattice view for $\mathrm{Tm}\left(\mathrm{PO}_{3}\right)_{3}$ constructed from the experimental single crystal diffraction data showing the main reflections and satellite reflections, as well as the Q-vector.

The monoclinic lattice symmetry and the observed reflection condition leads to the superspace group $C 2 / c(0 \beta 0) s 0$ or its non-centrosymmetric subgroup $C c(0 \beta 0) 0$. However, our structure refinement confirmed the centrosymmetric superspace group $C 2 / c(0 \beta 0) s 0$ to be more suitable than for $C c(0 \beta 0) 0$. As a trial, we used superspace group $C c(0 \beta 0) 0$ to refine the crystal structures but no lower $R$ values were given. Moreover, some $\mathrm{O}$ atoms within ' $C c(0 \beta 0) 0$ ' structure model are non-positive defined and thus we use superspace group $C 2 / c(0 \beta 0)$ $s 0$ to model compound $\mathrm{Tm}\left(\mathrm{PO}_{3}\right)_{3}$. In this nomenclature, the $C 2 / c$ component indicates that the $(3+1)$-D symmetry operations are derived from this 3-D space group, the " $(0 \beta 0)$ " indicate that the $\mathbf{q}$ vector have one components of $\mathbf{b}^{*}$, and the $s 0$ indicate that the 2 -fold axes of $C 2 / c$ space group have acquired an $x_{4}$ glide on moving to $(3+1)$-D space, and the mirror plane have not.

The structure solution generated one Tm atom, two $\mathrm{P}$ atoms and five $\mathrm{O}$ atoms in the asymmetric unit. All atoms are affected by positional modulations. The output of the charge-flipping procedure is a scattering density map that can be interpreted in terms of atomic positions by Jana2006 to locate in the density not only the atomic positions but also the modulation functions. After that, improvements to the model were made from inspection of the electron density maps surrounding the atomic positions where the initial assignments of the Jana2006 program did not suffice. Fourier syntheses indicated that, $\mathrm{Tb}^{1}, \mathrm{P}^{1}, \mathrm{P}^{2}$, $\mathrm{O}^{1}, \mathrm{O}^{2}, \mathrm{O}^{3}, \mathrm{O}^{4}$ and $\mathrm{O}^{5}$ atoms can be simply described by continuous positional modulation waves in the model (Fig. 3). The atomic displacement parameters of $\mathrm{Tb}^{1}, \mathrm{P}^{1}, \mathrm{P}^{2}, \mathrm{O}^{2}, \mathrm{O}^{3}$ and $\mathrm{O}^{4}$ are modulated whereas those of $\mathrm{O}^{1}$ and $\mathrm{O}^{5}$ are not. After adding some ADP modulation waves, the final refined converged to $R\left[F^{2}>2 \sigma\left(F^{2}\right)\right]=0.0478$ for all observed reflections 2158 (698 main, 1113 first order and 347 second order satellites). Moreover, difference Fourier syntheses using the final atomic parameters showed no significant residual peaks (highest residual peak of $2.12 e \cdot A^{-3}$ and highest residual hole of -2.34 $e \cdot A^{-3}$ ). This model was confirmed by a significant drop in the $R$ value and no significant difference Fourier peaks appeared. 

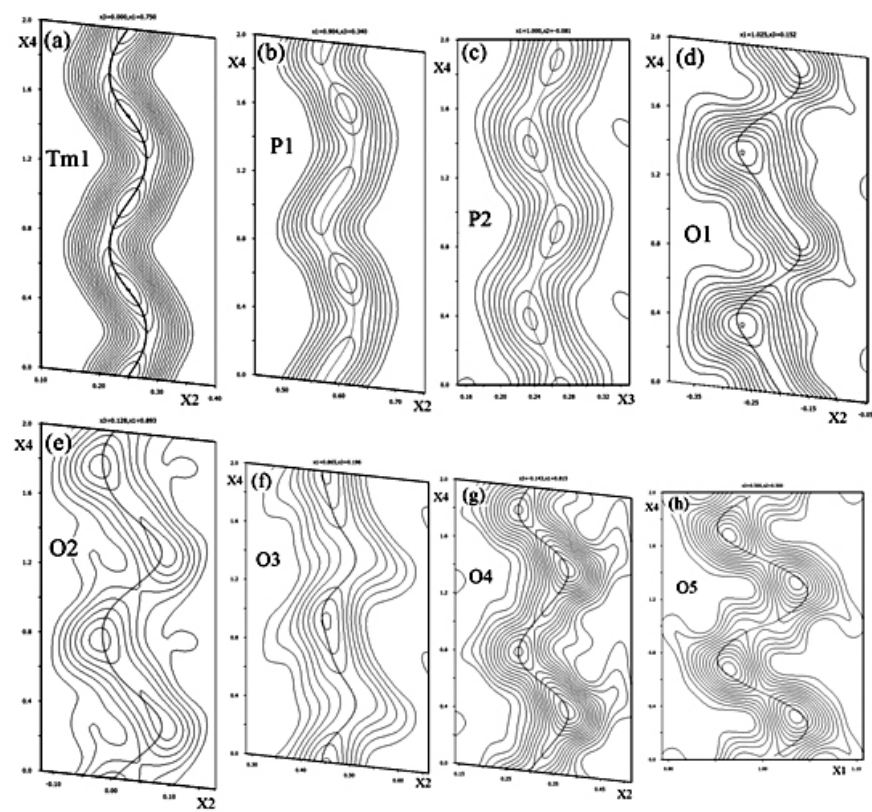

Figure 3. Positional modulations of $\mathrm{Tm}^{1}(\mathrm{a}), \mathrm{P}^{1}(\mathrm{~b}), \mathrm{P}^{2}(\mathrm{c}), \mathrm{O}^{1}(\mathrm{~d}), \mathrm{O}^{2}(\mathrm{e})$, $\mathrm{O}^{3}(\mathrm{f}), \mathrm{O}^{4}(\mathrm{~g})$ and $\mathrm{O}^{5}(\mathrm{~h})$ atoms in $\mathrm{Tm}\left(\mathrm{PO}_{3}\right)_{3}$ as functions of the internal $x_{4}$ axis through the superspace electron density.

Considering the modulation vectors $\mathbf{q}=0.358 \mathbf{b}^{*}$, we make the approximation of $0.365 \approx 6 / 17$, thus creating a periodic $17 \times b$ superstructure of the basic cell, as shown in Fig. 4. Within incommensurately modulated structure, the fluctuation of the atomic positions from the average structure as well as the variation of interatomic distances can be visualized as a function of an additional parameter $t$. In other words, the variations of bond distances caused by modulation can be observed as a function of $t$, the additional dimensional space coordinates. In Fig. 5, the $\mathrm{Tm}-\mathrm{O}$ and $\mathrm{P}-\mathrm{O}$ distances plotted as a function of $t$. We observe that the $\mathrm{PO}_{4}$ tetrahedra and $\mathrm{TmO}_{6}$ octahedra tend to have stable $\mathrm{P}-\mathrm{O}$ and $\mathrm{Tm}-\mathrm{O}$ distances, indicating that they form rather rigid entities. As listed in Tab. 2, the largest modulations for $\mathrm{P}-\mathrm{O}$ bonds are observed at the $\mathrm{P}^{1}-\mathrm{O}^{5}$, with a deviation of bond length $0.125 \AA$, whereas $\mathrm{Tm}-\mathrm{O}$ bonds have a differences below $0.076 \AA$. The $\mathrm{P}-\mathrm{O}$ and $\mathrm{Tm}-\mathrm{O}$ distances all fall in the tolerable range of inorganic Tm(III) and $\mathrm{P}(\mathrm{V})$ oxides. ${ }^{[18,19]}$

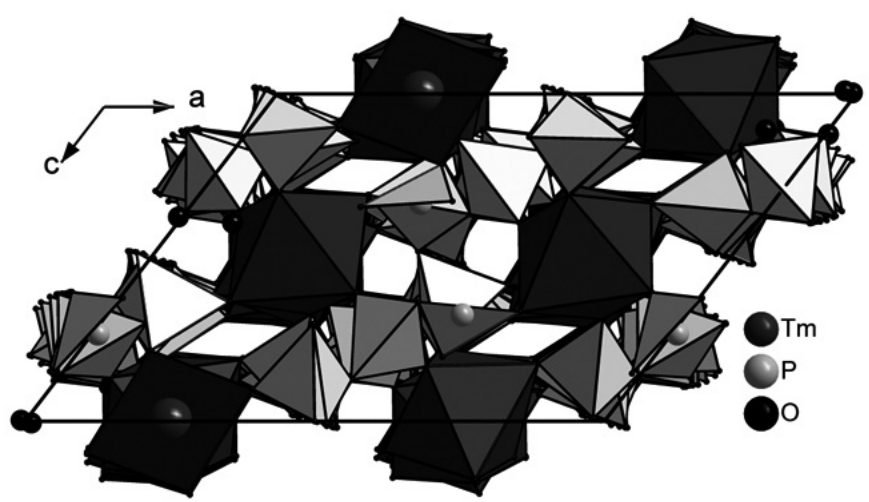

Figure 4. Approximant cell of incommensurate modulated structure of $\operatorname{Tm}\left(\mathrm{P}_{3} \mathrm{O}\right)_{3}$ viewed in the $17 \times b$ supercell along the $b$-axis.
Table 2. Geometric parameters $(\AA)$ of $\operatorname{Tm}\left(\mathrm{PO}_{3}\right)_{3}$.

\begin{tabular}{|c|c|c|c|}
\hline $\operatorname{Tm}\left(\mathrm{PO}_{3}\right)_{3}$ & Average & Minimum & Maximum \\
\hline $\mathrm{Tm}^{1}-\mathrm{O}^{2}$ & $2.200(17)$ & $2.160(19)$ & $2.236(19)$ \\
\hline $\mathrm{Tm}^{1}-\mathrm{O}^{2 \mathrm{i}}$ & $2.200(17)$ & $2.160(19)$ & $2.236(19)$ \\
\hline $\mathrm{Tm}^{1}-\mathrm{O}^{3}$ & $2.209(14)$ & $2.181(15)$ & $2.233(15)$ \\
\hline $\mathrm{Tm}^{1}-\mathrm{O}^{3 \mathrm{i}}$ & $2.209(14)$ & $2.181(15)$ & $2.233(15)$ \\
\hline $\mathrm{Tm}^{1}-\mathrm{O}^{4}$ & $2.20(3)$ & $2.19(3)$ & $2.22(3)$ \\
\hline $\mathrm{Tm}^{1}-\mathrm{O}^{4 \mathrm{i}}$ & $2.20(3)$ & $2.19(3)$ & $2.22(3)$ \\
\hline $\mathrm{P}^{1}-\mathrm{O}^{1 \mathrm{ii}}$ & $1.582(18)$ & $1.513(19)$ & $1.633(19)$ \\
\hline $\mathrm{P}^{1}-\mathrm{O}^{3}$ & $1.464(18)$ & $1.440(19)$ & $1.486(19)$ \\
\hline $\mathrm{P}^{1}-\mathrm{O}^{4 i i i}$ & $1.47(2)$ & $1.41(3)$ & $1.51(3)$ \\
\hline $\mathrm{P}^{1}-\mathrm{O}^{5}$ & $1.551(10)$ & $1.502(16)$ & $1.627(16)$ \\
\hline $\mathrm{P}^{2}-\mathrm{O}^{1}$ & $1.59(2)$ & $1.53(2)$ & $1.65(2)$ \\
\hline $\mathrm{P}^{2}-\mathrm{O}^{\text {liv }}$ & $1.59(2)$ & $1.53(2)$ & $1.65(2)$ \\
\hline $\mathrm{P}^{2}-\mathrm{O}^{2}$ & $1.466(15)$ & $1.408(17)$ & $1.518(17)$ \\
\hline $\mathrm{P}^{2}-\mathrm{O}^{2 \mathrm{iv}}$ & $1.466(15)$ & $1.408(17)$ & $1.518(17)$ \\
\hline $\begin{array}{l}\text { Symmetry codes: } \\
\text { (i) }-x_{1}+3 / 2,-x_{2}+1 / 2, \\
-x_{3},-x_{4} ;\left(\text { ii) }-x_{1}+2,\right. \\
x_{2}+1,-x_{3}+1 / 2, \\
x_{4}+1 / 2 ; \\
\text { (iii) } x_{1},-x_{2}+1, \\
x_{3}+1 / 2,-x_{4}+1 / 2 ; \text { (iv) } \\
-x_{1}+2, x_{2},-x_{3}+1 / 2, \\
x_{4}+1 / 2 .\end{array}$ & & & \\
\hline
\end{tabular}

In addition, it is useful to calculate the bond valence sums (BVS) for compound $\mathrm{Tm}\left(\mathrm{PO}_{3}\right)_{3}$ to evaluate the validity of the structure. ${ }^{[20]}$ The calculated average bond valences are 2.870(4), 5.127(19) and 5.015(14) respectively for $\mathrm{Tm}^{1}, \mathrm{P}^{1}$ and $\mathrm{P}^{2}$ atom $\mathrm{s}$.

In summary, the crystal structure of four-dimensional incommensurately modulated $\mathrm{Tm}\left(\mathrm{PO}_{3}\right)_{3}$ has been characterized through single crystal X-ray diffraction analysis. The results show that the basic structure of $\operatorname{Tm}\left(\mathrm{PO}_{3}\right)_{3}$ features a three-dimensional (3D) framework constructed by interconnected $\mathrm{PO}_{4}$ tetrahedra and $\mathrm{TmO}_{6}$ octahedra. The modulated structure was determined to be $(3+1)$-D superspace group $C 2 / c(0 \beta 0) s 0$ and modulation vector $\mathbf{q}=$ $0.358410 \mathbf{b}^{*}$. The structure was solved directly in superspace by the chargeflipping method and subsequently refined by the Jana2006 crystallographic computing system. The asymmetric unit of $\mathrm{Tm}\left(\mathrm{PO}_{3}\right)_{3}$ contains eight atoms, which are all affected by positional modulations. 

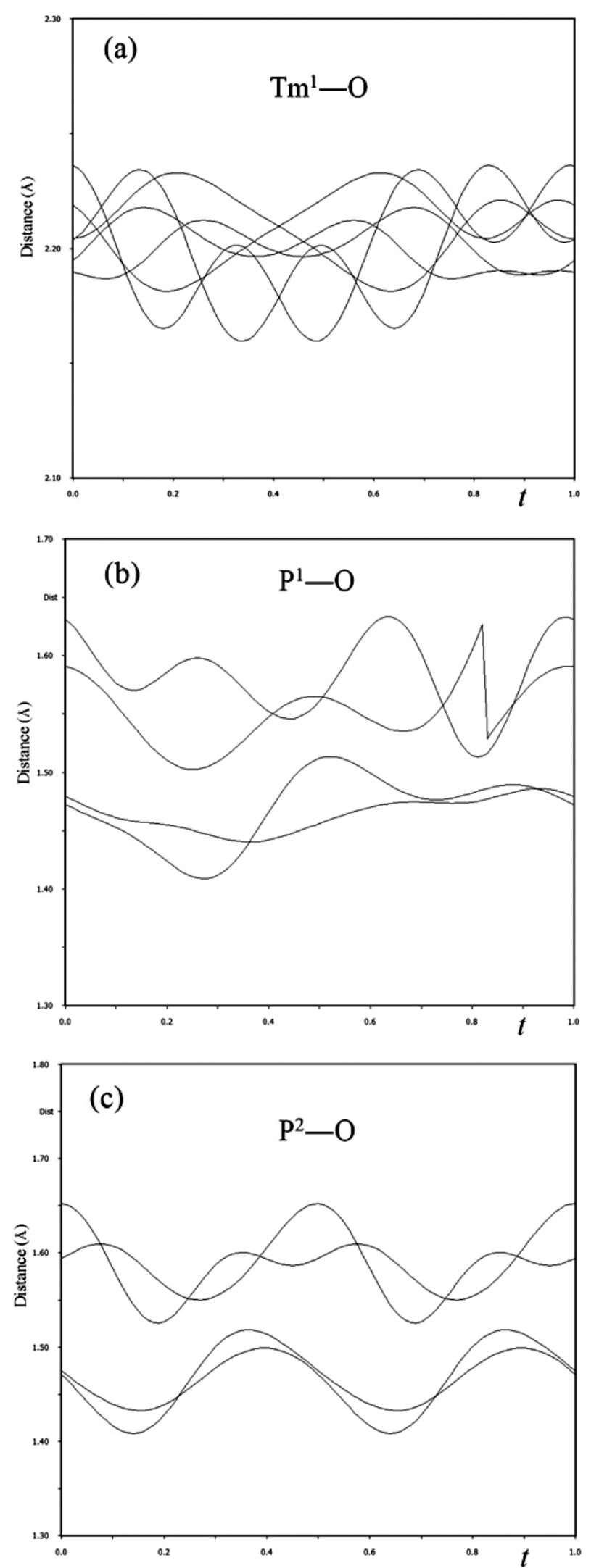

Figure 5. Interatomic Distances $(\AA)$ of $\mathrm{Tm}^{1}-\mathrm{O}$ bonds (a), $\mathrm{P}^{1}-\mathrm{O}$ bonds (b) and $\mathrm{P}^{2}-\mathrm{O}$ bonds (c) influenced by positional modulation.

\section{REFERENCES}

1.- N.-N. Wang, Z.-Z. He, M.-Y. Cui, W.-B. Guo, S.-Y. Zhang, M. Yang, Y.Y. Tang, Chin. J. Struc. Chem. 34(9), 1357 (2015)

2.- S.-Y. Zhang, W.-B. Guo, M. Yang, Y.-Y. Tang, M.-Y. Cui, N.-N. Wang, Z.-Z. He, Dalton Trans. 44(47), 20562 (2015)

3.- W. T. Chen, S. M. Ying, D. S. Liu, J. H. Liu, H. M. Kuang, J. Iran. Chem. Soc. 7(2), $510(2010)$

4.- W. T. Chen, R. A Hu, Y. F. Wang, X. Zhang, J. Liu, J. Iran. Chem. Soc. 11(6), 1649 (2014)

5.- J. Yang, X. Wang, X. Zhao, J. Dai, S. Mo, J. Phys. Chem. C 119(6), 3068 (2015)

6.- G. Yang, G. Peng, N. Ye, J. Wang, M. Luo, T. Yan, Y. Zhou, Chem. Mater. 27(21), 7520 (2015)

7.- S. Wang, N. Ye, J. Amer. Chem. Soc. 133(30), 11458 (2011)

8.- J.-N. Chotard, G. Rousse, R. David, O. Mentre, M. Courty, C. Masquelier, Chem.Mater. 27(17), 5982 (2015)

9.- D. Zhao, R.-H. Zhang, F.-F. Li, J. Yang, B.-G. Liu, Y.-C. Fan, Dalton Trans. 44(13), 6277 (2015)

10.- D. Zhao, R.-H. Zhang, F.-X. Ma, F.-F. Li, Mater. Lett. 157, 219 (2015),

11.- H. A. Hoeppe, Angew. Chem., Int. Ed. 48(20), 3572 (2009)

12.- H. N. Tong, H. Zhang, W. D. Cheng, D. S. Wu, Y. J. Gong, J. Zhu, S. P. Huang, D. Zhao, Chin. J. Struct. Chem. 26(3), 338 (2007)

13.- H. Naili, H. Ettis, S. Yahyaoui, T. Mhiri, Mater. Res. Bull. 41, 1990 (2006)

14.- H. A. Hoppe, S. J. Sedlmaier, Inorg. Chem. 46, 3467 (2007)

15.- Bruker. APEX2 and SAINT, Bruker AXS Inc., Madison, Wisconsin, USA, (2008)

16.- L. Palatinus, G. Chapuis, J. Appl. Phys. 40, 786 (2007)

17.- V. Petricek, M. Dusek, L. Palatinus, Z. Kristallogr. 229(5), 345 (2014)

18.- K. Yoshii, Mater. Res. Bull. 47(11), 3243 (2012)

19.- J. Zhu, H. Chen, Y. D. Wang, S. Zhang, W. D. Cheng, H. T. Guan, Chin. J. Struc. Chem. 30(5), 648 (2011)

20.- N. E. Brese, M. O’Keeffe, Acta Crystallogr. B. 47, 192 (1991) 